\title{
Identifying pathophysiological bases of disease in COVID-19
}

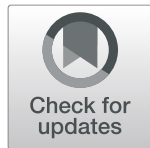

Carla J. Goldin ${ }^{1,2}$, Ramiro Vázquez ${ }^{3,4}$, Fernando P. Polack ${ }^{1}$ and Damian Alvarez-Paggi $1^{12^{*}}$ (D)

\begin{abstract}
COVID-19 is an infectious disease caused by the SARS-CoV-2 virus that can affect lung physiology encompassing a wide spectrum of severities, ranging from asymptomatic and mild symptoms to severe and fatal cases; the latter including massive neutrophil infiltration, stroke and multiple organ failure. Despite many recents findings, a clear mechanistic description underlying symptomatology is lacking.

In this article, we thoroughly review the available data involving risk factors, age, gender, comorbidities, symptoms of disease, cellular and molecular mechanisms and the details behind host/pathogen interaction that hints at the existence of different pathophysiological mechanisms of disease. There is clear evidence that, by targeting the angiotensin-converting enzyme II (ACE2) -its natural receptor-, SARS-CoV-2 would mainly affect the reninangiotensin-aldosterone system (RAAS), whose imbalance triggers diverse symptomatology-associated pathological processes. Downstream actors of the RAAS cascade are identified, and their interaction with risk factors and comorbidities are presented, rationalizing why a specific subgroup of individuals that present already lower ACE2 levels is particularly more susceptible to severe forms of disease. Finally, the notion of endotype discovery in the context of COVID-19 is introduced.

We hypothesize that COVID-19, and its associated spectrum of severities, is an umbrella term covering different pathophysiological mechanisms (endotypes). This approach should dramatically accelerate our understanding and treatment of disease(s), enabling further discovery of pathophysiological mechanisms and leading to the identification of specific groups of patients that may benefit from personalized treatments.
\end{abstract}

Keywords: SARS-CoV-2, COVID-19, Pathophysiology, RAAS, Risk factors, Comorbidities, Endotypes

\section{Introduction}

The recently described SARS-CoV-2 virus is the latest addition into the group of pathogenic human coronaviruses $(\mathrm{HCoV})$. The Coronavirinae subfamily encompasses four different genera: alpha, beta, gamma and deltacoronavirus. The genetic and serologic groups alfaand betacoronavirus includes pathogens that mainly infect mammals (except pigs) [1]. The normally circulating 229E and NL63 are alphacoronaviruses whereas OC43 and HKU1 are betacoronaviruses. During the last twenty years, three additional $\mathrm{HCoVs}$ from zoonotic origin have surfaced: SARS-CoV, MERS-CoV and SARS-CoV-2,all

\footnotetext{
* Correspondence: dalvarezpaggi@infant.org.ar

${ }^{1}$ INFANT Foundation, Buenos Aires, Argentina

${ }^{2}$ CONICET, Buenos Aires, Argentina

Full list of author information is available at the end of the article
}

belonging to the betacoronavirus genus. While the usual $\mathrm{HCoV}$ are normally associated with common cold symptoms, these last pathogens may elicit infections that range from asymptomatic carrier to severe pneumonia, leading to acute respiratory distress syndrome (ARDS). A common feature of SARS-CoV and SARS-CoV-2 is that viral attachment occurs via interaction of the viral spike $(S)$ protein - which is primed by the Transmembrane Serine Protease 2 (TMPRSS2) - to the host angiotensinconverting enzyme 2 (ACE2), allowing viral entry $[2,3]$. Interestingly, this feature is shared with the NL63 HCoV, while the other $\mathrm{HCoVs}$ employ different receptors such as dipeptidyl peptidase 4 and aminopeptidase N [4]. The $\boldsymbol{S} /$ ACE2 interaction gives place to a cross-talk point between viral infection and the renin-angiotensin-aldosterone

(c) The Author(s). 2020 Open Access This article is licensed under a Creative Commons Attribution 4.0 International License, which permits use, sharing, adaptation, distribution and reproduction in any medium or format, as long as you give appropriate credit to the original author(s) and the source, provide a link to the Creative Commons licence, and indicate if changes were made. The images or other third party material in this article are included in the article's Creative Commons licence, unless indicated otherwise in a credit line to the material. If material is not included in the article's Creative Commons licence and your intended use is not permitted by statutory regulation or exceeds the permitted use, you will need to obtain permission directly from the copyright holder. To view a copy of this licence, visit http://creativecommons.org/licenses/by/4.0/. 
system (RAAS), and there is mounting evidence that this interplay may crucially affect disease severity (see below).

SARS-CoV-2 causes COVID-19, a disease that presents a wide range of clinical manifestations, from asymptomatic to severe ARDS and may result fatal due to respiratory insufficiency, stroke, thrombotic complications [5] and, finally, multi organic failure [6]. Although an accurate mechanistic description is lacking, it is proposed that an uncontrolled and excessive release of proinflammatory cytokines (called "cytokine storm") may cause some of the symptoms, including shock and tissue damage, and massive neutrophil infiltration [7]. Current consensus is that older people, immunocompromised or patients with significant underlying conditions and comorbidities such as diabetes and hypertension are more likely to experience severe COVID-19 symptoms [8].

Assessment of the mechanisms underlying SARS$\mathrm{CoV}$-2-induced disease and severity has focused mainly on the immunopathological features $[7,9,10]$, and have resulted in some unexpected findings: the unusual seroconversion processes involving IgM and IgG titers among infected patients [11], the age-dependent cytokine storm-induced reduction and functional exhaustion of $\mathrm{CD}_{4}^{+}$and $\mathrm{CD}^{+} \mathrm{T}$ cells - both critical to eliminate virus-infected cells and for achieving successful recovery [12] - , and the possible link between severity and genetic variations in chemokine receptors and blood group loci [13], among others. These findings clearly hint at the existence of distinct pathophysiological bases of disease in COVID-19. In addition, other actors have been identified or proposed, such as endocrine and metabolic pathways [14] and the role of infected endothelial cells [15] in disease severity. However, a comprehensive and cohesive evaluation of these factors is lacking. In the following sections, we present a detailed review attempting to identify molecular bases of disease severity based on the specifics of host/pathogen interplay, with an emphasis on the endocrine-immune interactions involved. Finally, we speculate that COVID-19 is actually an umbrella term that includes several pathophysiological mechanisms, known as endotypes, originated in the individual-specific host/pathogen interactions, which simultaneously depend on the functional status of the RAAS.

The entry point of SARS-CoV-2: ACE2 and TMPRSS2 ACE2 is a central component of the RAAS

The coronaviruses SARS-CoV, SARS-CoV-2 and NL63CoV rely on binding of their $S$ protein to ACE2 $[2,16]$ for attachment and cell entry, being able to infect many of the organs where it is expressed [17-19]. Human ACE2 is a transmembrane enzyme that contains different functional domains: a $C$-terminal anchoring region, a $\mathrm{N}$-terminal signal peptide region, and an extracellular
HEXXH zinc-binding metalloprotease domain [20-22]. ACE2 is a member of the RAAS, that involves a variety of hormones and enzymatic reactions whose primary role consists of regulating the homeostasis of the cardiovascular and renal systems [23, 24], playing also a critical function in inflammatory response [25]. This system consists of two main axes: the classic angiotensin-converting enzyme (ACE)-angiotensin IIAT1 receptor, and the ACE2-angiotensin-(1-7)-Mas receptor axis, that was discovered rather recently (Fig. 1).

Both ACE and ACE2 are found in the cytoplasmic membrane of arterial and venous endothelial cells, and arterial smooth muscle cells $[26,27]$. ACE2 is expressed in several organs such as the heart, kidney, lung and testes, among others $[17,19]$. In particular, it is present in human nasal epithelium, alveolar and small intestinal cells [28]. ACE and ACE2 have been largely studied as pivotal members of the RAAS. As shown in Fig. 1, they play antagonistic roles by processing the renin-cleaved decapeptide angiotensin both competitively or in an alternate fashion. The main role of ACE2 is countering ACE activity by reducing angiotensin 2 (AngII) -a potent vasopressor and sodium-and-water retaining octapeptide- bioavailability and increasing angiotensin-(17) (Ang-(1-7)) formation -a vasodilator and diuretic peptide-, although alternative catalytic pathways exist [29-31]. In this context, an imbalance in ACE2/Ang-(17) and ACE/AngII axes may be critical in the development of cardiovascular diseases [32]. Activation of the ACE-mediated classic axis leads to deleterious effects: vasoconstriction, fibrosis, migration, fluid retention, thrombosis and inflammation; on the other hand, the ACE2-centered via exerts protective vasodilation, and antithrombotic, antiarrhythmic and anti-inflammatory actions [33, 34].

\section{$S$ induces downregulation of ACE2 after complex formation}

The extracellular domain of ACE2 can be cleaved from the transmembrane domain by at least two different enzymes, ADAM metallopeptidase domain 17(ADAM17) and TMPRSS2, and the resulting soluble protein is released into the bloodstream and ultimately excreted into urine [3, 35]. TMPRSS2 is a type II transmembrane serine protease expressed in the airway epithelial cells and several tissues. It participates not only in SARSCoV-2 infection, but is also required by other respiratory viruses such as human influenza and metapneumoviruses [36, 37]. TMPRSS2 increases the infective capacity of both NL63 $S$ - and SARS CoV $S$ - pseudotyped HIV as well as authentic SARS-CoV and SARS-CoV-2, even in cells with low levels of ACE2 expression, inducing ACE2 shedding and thereby loss of its physiological 


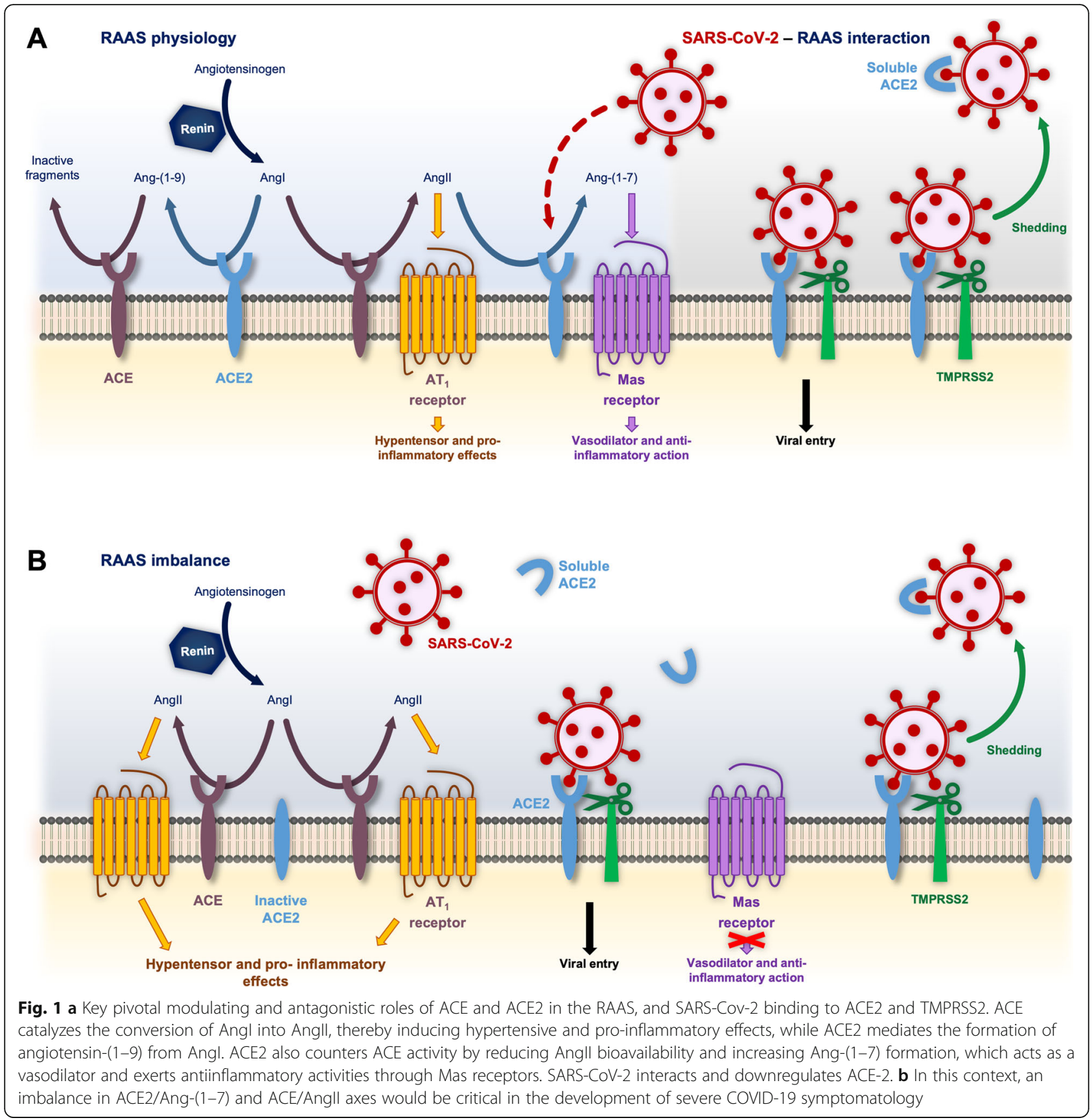

function [2, 37-39] (Fig. 1). The role of TMPRSS2 enabling viral entry would consist of: i) ACE2 cleavage, promoting viral uptake, and ii) $S$ cleavage in two distinct sites, allowing viral fusion to a host membrane [3, 37, 40]. In the case of SARS-CoV, both mechanisms are independent since ACE2 processing by TMPRSS2 is necessary to increase SARS-CoV $\boldsymbol{S}$-driven entry but is dispensable for SARS-CoV $S$ activation [3]. In addition, SARS-CoV $\boldsymbol{S}$ and, to a lesser extent, NL63-CoV $\boldsymbol{S}$ can also induce ADAM-17 dependent cleavage of ACE2 in vitro $[38,39]$.
The interaction energies of different $\mathrm{CoV} S$ proteins with ACE2 have been shown to follow a NL63-CoV $<<$ SARS-CoV $<$ SARS-CoV-2 [41, 42] order due to overlapping but not identical binding interfaces and amino acid variations in the $S$ protein among the different viruses $[42,43]$. Interestingly, although the interaction energy between SARS-CoV-2 receptor binding domain (RBD) and ACE2 is higher than that observed for SARS-CoV RBD, SARS-CoV-2 RBD is less accessible, resulting in similar apparent binding affinities [44]. The interplay between $\boldsymbol{S}$ and ACE2 complex formation and the 
activation of host proteases suggests that although the viral entry mechanisms are similar between NL63-CoV, SARS-CoV and SARS-CoV-2, ACE2 downregulation levels might correlate with the binding affinities involved in complex formation, which may play a key part in COVID-19 symptomatology.

\section{SARS-CoV-2-induced RAAS imbalance results in inflammation and other severe COVID-19 symptoms}

The role of unbalanced RAAS as a central player in ARDS and acute lung injury is nowadays well established [45]. ACE-generated AngII triggers inflammatory processes, stimulating proliferation of mononuclear cells and regulating the recruitment of proinflammatory cells (by expressing vascular permeability factors and adhesion molecules, among others) [46], rendering the AngII-degrading ACE2 as an essential actor for homeostasis. ACE2-deficient animals are significantly more susceptible to severe pulmonary damage in the context of SARS coronavirus, Influenza H7N9 virus or bacteria infections, as well as LPS inhalation [47-50]. These facts hint at a counterintuitive role of ACE2 expression levels in determining the severity of SARS-CoV-2 infection: although SARS-CoV-2 entry is dependent on ACE2, it is established that lower levels of this molecule can cause exacerbated inflammation, at least to some extent. In mice, during lung infection the initial reduction of pulmonary ACE2 is crucial for recruiting the inflammatory neutrophils to combat the infection, and the subsequent recovery of pulmonary ACE2 is critical to prohibit exuberant neutrophil accumulation. It was found that ACE2 modulated neutrophil infiltration through IL-17mediated STAT3 signaling, which also recruits factors from the inflamed microenvironment [48]. Confounding factors that either prevent the ACE2 dynamics from occurring or disrupt it are detrimental to the host, resulting in either compromised host defense capability or heightened inflammatory lung diseases [48]. Evidence shows that SARS-CoV $\boldsymbol{S}$ protein, which is not infective, exerts proinflammatory effects: intraperitoneally inoculation with recombinant SARS-CoV $S$ worsens the severity of acid aspiration-induced acute lung injury in wild-type mice [47], increasing AngII levels in the lungs. Furthermore, when AngII receptor type 1 (AT1R) was blocked, acute lung injury in $\boldsymbol{S}$ treated mice was attenuated [47]. Complement system also plays a role: infection of $\mathrm{C} 3$ deficient mice with mouse-adapted SARS-CoV exhibited less respiratory dysfunction and fewer neutrophils, inflammatory monocytes and lower cytokine levels in lungs than wild-type mice [51].

Endothelial cells continuously express ACE2, constituting an optimal infection target for SARS-CoV and
SARS-CoV-2 [52, 53]. This allows infection spreading and affects the RAAS ecosystem of each organ, and entails direct injury in the endothelium leading to endotheliitis [53], higher vascular permeability and hemostatic dysfunction [54]. In addition, such constitutive expression would explain the significant thrombotic disorders recently reported in the autopsies of COVID-19 patients [55]. In addition, many of the observed severe symptoms or causes of death are represented over different organs. The major complications observed are ARDS [56-60], acute cardiac injury [56, 58,60], heart failure [56, 61], shock [56, 58, 60], acute kidney injury [56, 58-60], hypoxic encephalopathy [56], lymphopenia [60] and acute pulmonary embolism [62], which could all be at least partially ascribed to disbalancing of the RAAS.

Recent studies have shown a high incidence of neurological symptoms in COVID-19 cases. Although most of them are minor (like headache, nausea, and a loss of sense of smell and taste), more complicated symptomatology, such as convulsions, stroke and thrombotic complications have been also reported [63-65]. There is a strong possibility that these complications arise, at least in part, from downregulation of ACE2. It is now heavily documented that one of the important effects of ACE2 /Ang-(1-7)/mas receptor axis is on the brain and cerebral blood vessels [66], exerting protection against stroke [67] and there is evidence supporting the overall concept that the aging increases the sucseptivility of the cerebrovasculature to the effects of RAAS disbalance [68].

Taking into account the results obtained in mice models and SARS-CoV, and its similarities with SARS$\mathrm{CoV}-2$, there is strong evidence that differences in expression levels of ACE2 in the context of SARS-CoV-2 infection may constitute a molecular basis of exacerbated inflammation (Fig. 2). This is further supported by the observation that patients with severe COVID-19 show an increase in neutrophil count and in the neutrophil-to lymphocyte ratio and elevated levels of proinflammatory cytokines [7], consistent with in vivo results of neutrophil infiltration after ACE2 downregulation [48]. Moreover, a correlation between the ratio of pro- and anti-inflammatory cytokine concentrations and symptom severity has been observed [69]. It can be speculated that only a few cases of HCoV-NL63induced severe cases have been reported due to the lower $S$ /ACE2 complex affinity that results in milder dysregulation of ACE2 levels. However, patients with a subgenotype of HCoV-NL63 were hospitalized with severe lower tract infection in 2018. That subgenotype presented one mutation in its RBD that enhances viral entry into host cells, hinting at ACE2 downregulation underlying the severe symptomatology [70]. Furthermore, another few cases of HCoV-NL63-positive patients (82 yo median age) emerged, showing distress 


\section{ACE2 expression levels and pathophisiology of disease}

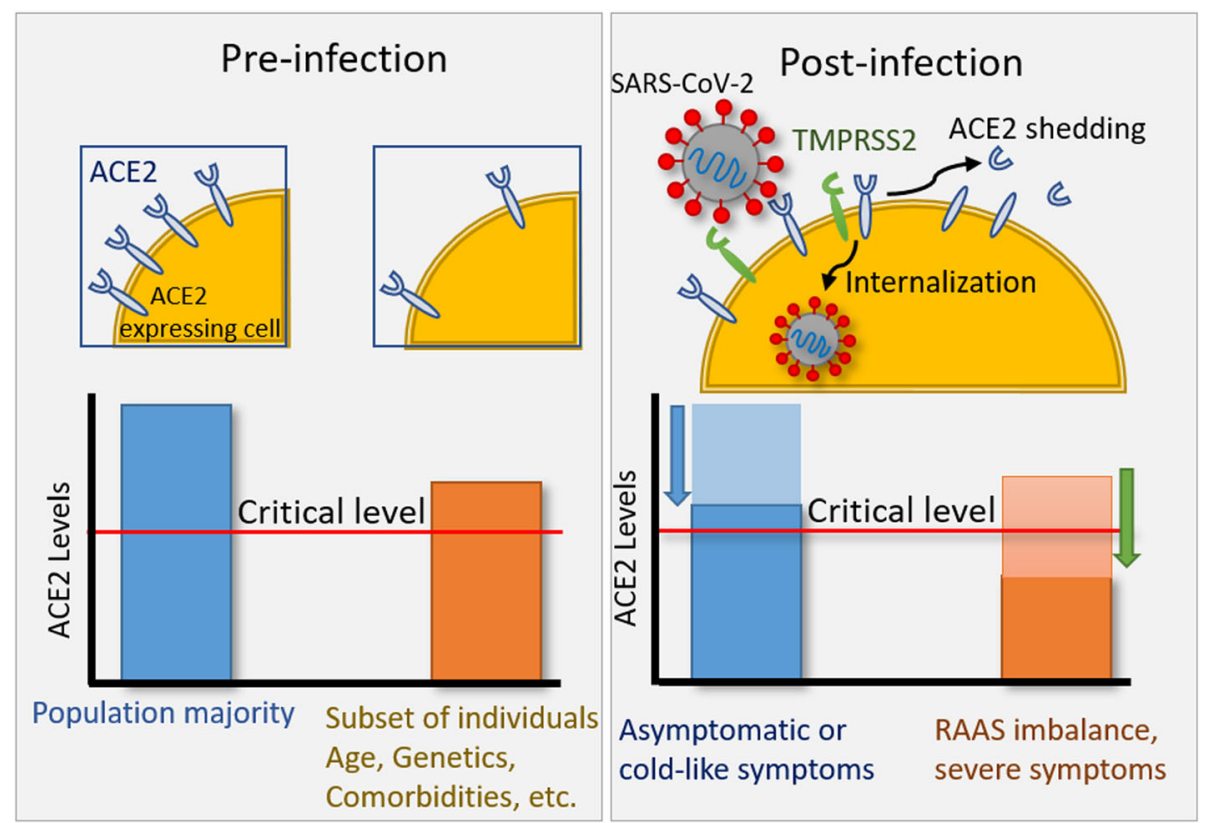

Fig. 2 The effect of ACE2 expression levels on COVID-19 disease and severity. Age, genetics, and different comorbidities affect the pre-infection ACE2 expression levels in a subset of individuals (left), rendering them susceptible to severe forms of disease. During infection (right), upon interaction of SARS-CoV-2S protein with ACE2 and TMPRSS2, ACE2 levels are downregulated. Those individuals with low pre-infection ACE2 levels reach a threshold critical value corresponding to the onset of severe symptomathologies due to RAAS imbalance

syndrome, with symptoms including pneumonia, multiple organ failure and death, although the subgenotype is unknown [71, 72].

Crucially, the RAAS presents a complex interplay with cyclooxygenase-2 (COX-2 [73, 74]) which is rapidly inducible in several cell types in response to growth factors, cytokines, and pro-inflammatory molecules. It is largely responsible for the onset of inflammation, participating in the synthesis of proinflammatory prostaglandins and triggers production of other proinflammatory chemokines and cytokines, and playing a role in hypertension [75]. Interestingly, while inhibition of COX-2 expression exerts a suppressive effect on lung inflammation [76], it has been shown that both $S$ and the nucleoprotein $(\boldsymbol{N})$ of SARS-CoV upregulate COX-2 [77] through different molecular mechanisms. Considering the high identity sequence of $S$ and $N$ proteins between both viruses (75 and 90\%, respectively [78]), SARS-CoV-2 may also elicit upregulation of COX-2, further exacerbating inflammation.

Finally, ACE genotypes may affect the SARS-CoV-2/ RAAS interplay. A critical ACE polymorphism consists of the presence (insertion, I) or absence (deletion, D) of a 287-bp Alu sequence in intron 16 [79], being the $\mathrm{D}$ allele associated with increased activity [80]. Intensive unit care patients bearing the $\mathrm{D}$ allele or $\mathrm{DD}$ genotype are more susceptible not only to develop ARDS, but also to present a less favourable outcome [81], with a higher risk of mechanical ventilation [82-84]. Interestingly, the $\mathrm{D}$ allele was in a higher frequency in those patients who developed the most severe symptoms of SARS-CoV infection [82]. In addition, a recent analysis of the prevalence of ACE (I/D) genotype in different countries showed that as the I/D allele frequency ratio increases, the COVID-19 recovery rate in each country also increases [85].

\section{Pathophysiological contributions of COVID-19 risk factors \\ Hypertension and diabetes}

Despite the large number of SARS-CoV-2 positive patients, understanding COVID-19 pathogenesis remains elusive. Available reports indicate that the most frequent comorbidity in severe COVID-19 is hypertension, followed by diabetes and coronary heart disease [86]. Reports on the clinical characteristics of patients with COVID-19 show that 2.5 to $14.5 \%$ of SARS-CoV- 2 positive patients present cardiovascular diseases, 12,8 to $56.6 \%$ of patients present hypertension and 5.3 to $33.8 \%$ patients have diabetes [87].

Ang-(1-7) has multiple beneficial cardiovascular effects: protection against heart failure, natriuretic and antithrombotic, among others [88]. In a mice model of ang II-dependent hypertension, blood pressures were higher 
in the ACE2-deficient mice than in wild-type specimens [89]. ACE2 expression in heart is also necessary for structural and functional regulation. After a myocardial infarction, ACE2-deficient mice presented an enhanced susceptibility to a second event, with increased mortality, infarct expansion and adverse ventricular remodeling. Loss of ACE2 also led to increased neutrophil infiltration in the infarct and peri infarct regions, resulting in upregulation of inflammatory cytokines [90].

The kidney is highly sensitive to RAAS perturbation. Several studies demonstrated an increased activity of this system involved in the development and progression of diabetic renal damage [91]. In mice models of either type 1 and type 2 diabetes mellitus, ACE2 expression is elevated in early stages of diabetic nephropathy while decreasing in the late phase of the disease, suggesting that ACE2 may participate in a compensatory mechanism in the diabetic kidney prior to illness onset [92]. Moreover, in a murine model of diabetic nephropathy, recombinant ACE2 administration improves kidney function and structure [93]. In agreement with these results, it was shown that ACE2 expression is decreased in the tubules in human diabetic nephropathy [94]. The imbalance of the RAAS system in favor of AngII in the context of diabetes results in a more severe kidney damage in males than in females, which is even increased if ACE2 is downregulated $[95,96]$.

\section{Age}

Age is a major factor affecting the severity of COVID-19 disease, correlating with both susceptibility to infection and manifestation of clinical symptoms. Therefore, incidence of clinical cases in countries with younger populations is expected to be lower than older population countries, despite the prevalence of other comorbidities [97]. It has been proposed that AT1R-mediated signaling is involved in the aging process per se by promoting several age-related pathologies, such as cardiovascular diseases, diabetes, chronic kidney failure, dementia, osteoporosis and even cancer [98, 99]. Increased AngII bioavailability due to reduced catabolism may result in overactivation of these receptors. In line with this, several authors have observed that ACE2 expression levels are reduced with age $[26,100,101]$.

ACE and ACE2 exert catalytic effects on several proteins beyond the RAAS. This apparent promiscuity confers these enzymes enough plasticity to reach the same physiological effects through alternative pathways, thereby producing quicker, more intense and coordinated responses. Thus, age-related alteration in the ACE/ACE2 activity does not only affect the physiology of the RAAS, but also another particular system in which both proteins have a prominent role: the kininogen-kinin-kallikrein (KKK). As shown in Fig. 3a,
ACE has been demonstrated to be one of the primary proteases responsible for the hydrolysis of the kinin bradykinin and, to a lesser extent, its derivative des$\mathrm{Arg}^{9}$-bradykinin. It is worth remarking that $\mathrm{ACE}$ is considered first a kininase, being known as kininase II [102], and then an angiotensinase, due to its " 80 -fold higher affinity for bradykinin with respect to AngI (4). In fact, the cough presented by some patients treated with ACE inhibitors has been attributed to the blockade of the bradykinin metabolism [103]. ACE2, on the other hand, degrades des-Arg ${ }^{9}$-bradykinin but no other forms of bradykinin (4). There are two types of kinin receptors: BR1, selectively sensitive to kinins lacking the Cterminal Arg residue like des-Arg ${ }^{9}$-bradykinin; and BR2, optimally stimulated by the full sequence of bradykinin. While BR2 is constitutive and widely expressed in different tissues and mediates vasodilator and antiinflammatory effects, the gene encoding BR1 is regulated by a promoter region with binding sites for transcription factors such as the activator protein-1 and the nuclear factor kappa B (NFkB), which are up-regulated during inflammation [104]. By acting on BR1 receptors, des$\mathrm{Arg}^{9}$-bradykinin induces vasocontraction and proinflammatory actions [104]. Thus, SARS-CoV-2 infection would favor the overactivation of the BR1 with deleterious effects in the affected tissue (Fig. 3b). In agreement with this, recent works point out to des-Arg ${ }^{9}$-bradykinin as a key mediator of lung injury caused by LPS [104, 105]. By employing ACE2-deficient mice, Sodhi and collaborators found that this enzyme is crucial in counteracting such mechanism giving its ability to inactivate des-Arg ${ }^{9}$-bradykinin, and thus the BR1 signaling [105]. Moreover, these authors reported that LPS-mediated inflammation downregulated ACE2 bioavailability by a NFkB-involved mechanism. Of note, AngII induces NFkB expression through AT1R [45].

Aging does not only affect the KKK system through the ACE/ACE2 balance, but also directly altering the pharmacology of BR1 and BR2. It has been observed that although the serum levels of kinins increase with age, the responsiveness of target cells is limited or altered [106]. In this respect, bradykinin-induced vasorelaxation is actually affected by the BR1/BR2 ratio in the vasculature [107]. In older subjects, the density of BR2 is reduced whereas that of pro-inflammatory BR1 seems to be elevated, thereby changing the balance towards a vasoconstrictor response [108] that could result more deleterious in the context of SARS-CoV-2 infection. Most tellingly, both aging and kinins up-regulate the expression of pro-inflammatory COX-2 in several tissues [109-111].

In summary, the aging-related re-adaptation of the RAAS, KKK and COX-2 pathways may put older people in a new equilibrium situation much more sensitive to 


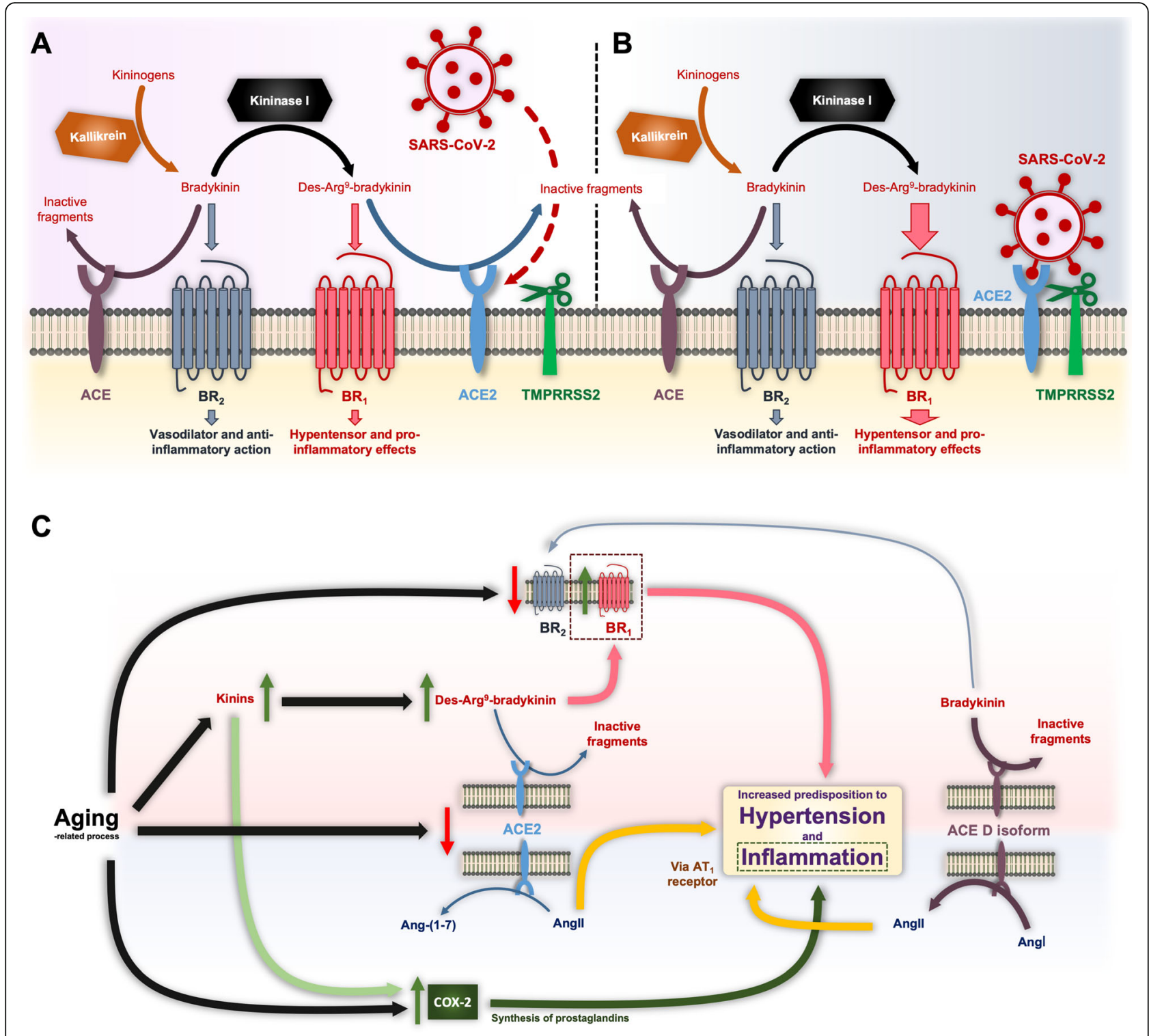

Fig. 3 a Action of ACE and ACE2 enzymes in the KKK system. ACE degrades bradykinin, a vasodilator peptide acting mainly through BR2 receptors. This kinin can be also converted by kininase I into des-Arg9-bradykinin, which promotes vasoconstriction and pro-inflammatory effects upon interaction with BR1 receptors. ACE2 participates in the degradation of des-Arg9-bradykinin, a process eventually inhibited by SARS-CoV-2induced ACE2 downregulation. b SARS-CoV-2-mediated imbalance in the KKK system with predominant pro-inflammatory effect of des-Arg9bradykinin. c Age-related variations in the RAAS, KKK system and COX-2 and ACE D isoform as enhancers of the susceptibility of older adults to present severe COVID-19 symptoms

minor fluctuations and with a limited margin of response, rendering them more susceptible to inflammatory processes. These mechanisms and the ACE isoform $\mathrm{D}$ are summarized in Fig. 3c as crucial factors increasing COVID-19 severity.

\section{Conclusions: towards endotypification of COVID-19}

We are experiencing the first global pandemic since the dawn of precision medicine: an approach that leaves out a "one-drug-fits-all" model, in favor of customization of healthcare. In this context, identifying different endotypes - subtypes of a condition with different underlying pathophysiological mechanisms - should become central for clinical research because it helps to rationalize experimental results and enhances reproducibility: heterogeneous groups of patients consisting of varying unidentified endotypes are prone to obfuscate statistical analysis of clinical trials for potential vaccine candidates and therapeutic treatments and hinder the identification of different factors that modulate disease severity, among 
others. Endotype discovery has been particularly successful in the treatment of other respiratory illnesses, such as asthma [112] and bronchiolitis [113, 114] usually combining trajectory analysis of meaningful variables along time, cytokine profiles and multi-omics analysis. We speculate there is mounting evidence showing that COVID-19, with its associated degrees of severity and heterogeneous symptomatology, is actually an umbrella term that may include several endotypes (Fig. 4). The available data about age, gender, genotypes, polymorphisms, comorbidities and symptoms of disease points to the existence of different endotypes, with a probable central role of the RAAS involved in severe cases. Most SARS-CoV-2 cases are asymptomatic, with reports ranging between 50 to $70 \%$ of total cases [103]. The remaining occurrences are further split between mild, presenting cold-like symptoms, and severe cases. Considering the current lack of absolute numbers regarding total infections, it is likely that the percentages of severe cases are overestimated, and these may be further subdivided between i) those with other underlying factors, ii) others that are aggravated by comorbidities, and iii) those that are specifically affected by imbalance of the RAAS throughout the infection process. We hypothesize that there is a strong possibility that this particular subset of individuals are thrown off-balance by SARS-CoV2 infection, constituting a distinctive endotype. For these

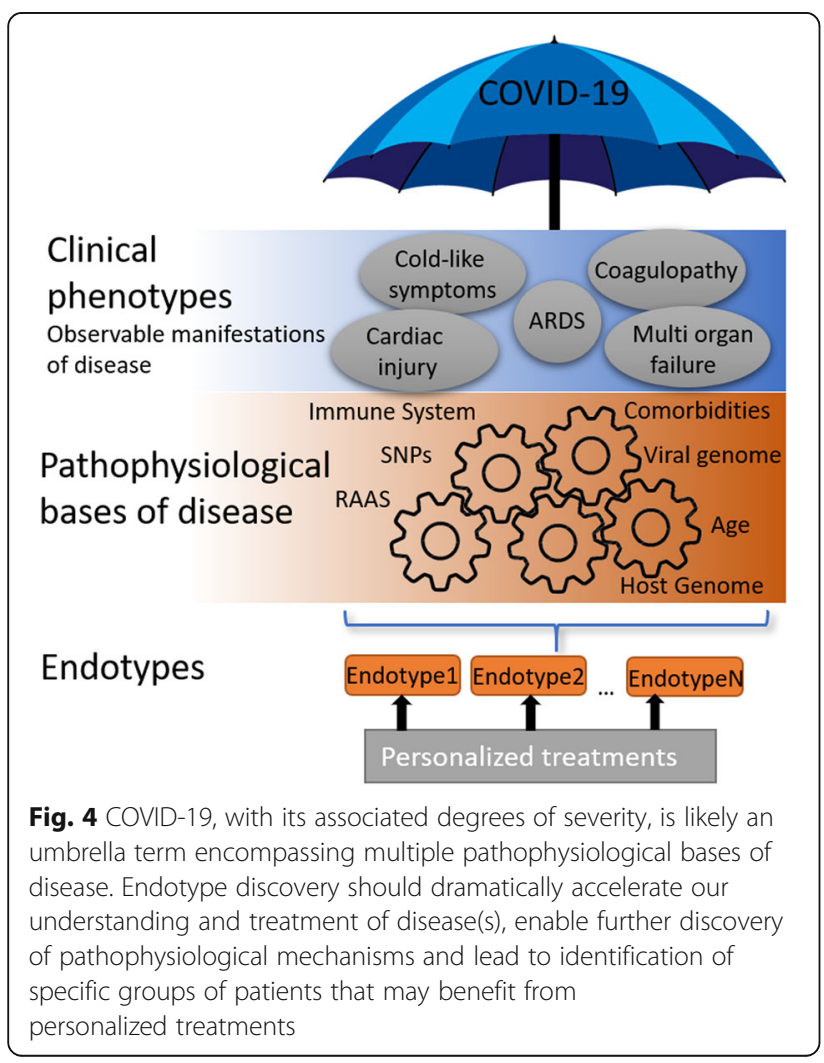

patients, personalized treatments should address critical open questions such as how to manage ACE inhibitors [115] that are used in clinical practice for treating hypertension and other cardiovascular diseases: Although ACE inhibitors do not interfere directly with ACE2 activity [17], discrepancies exist regarding their effects on ACE2 expression levels in different tissues [116-118] raising the question of whether these drugs would be harmful for COVID-19 patients. Despite this, current consensus is to continue treatment until conclusive data emerge [119-121].

A constellation of factors may underlie the particular susceptibility of a RAAS-imbalanced endotype. Single nucleotide polymorphism (SNP) present in ACE2 can be classified as harmful or protective, depending on their effect on the binding affinity of the S/ACE2 complex [122], rendering them as possible factor underlying severity across different populations [123]. Aging may predispose to an exacerbated inflammatory response by downregulation of ACE2 and upregulation of COX-2, and gender, genotypes, SNPs and hypertension may play similar roles. Differences in the prevalence of comorbidities among sex -males are more likely to present comorbidities than females- may also partially explain the increased incidence ( 44 to $76 \%$ in males vs 24 to $56 \%$ in females) and mortality (55 to $64 \%$ in males vs 36 to $45 \%$ in females) observed in COVID-19 male patients [124]. These factors are expected to intersect at the regulation of ACE2: low expression levels render individuals particularly vulnerable to SARS-CoV-2, that in turn further downregulates ACE2 levels through shedding, critically affecting RAAS, bradykinin and COX-2 function. In particular, COX-2 may directly be affected by the interaction with $N$ and $S$ proteins. This is expected to onset proinflammatory mechanisms that are likely to establish a positive feedback with the ongoing viral infection, thus resulting in pneumonia and the observed cytokine storm, prothrombotic activity, and many of the severe symptoms detected in COVID-19. Although lower levels of ACE2 expression may seem protective as it would hinder viral entry, they appear to play a key role in the onset of severe symptomatology.

Other identified or proposed key factors that must be considered to identify different underlying endotypes include antibody-dependent enhancement [125], the role of previous infections with other coronaviruses, immunological profiles and genetic variations [9, 11-13]. A critical discussion of risk factors, comorbidities, pathophysiological basis of disease and their translational applications within the appropriate theoretical framework is prone to enable better understanding of the molecular basis of disease and, therefore, the design of successful strategies for personalized treatments. 


\section{Abbreviations}

ACE: Angiotensin-converting enzyme; ACE2: Angiotensin-converting enzyme Il; ADAM17: ADAM metallopeptidase domain 17; Ang-(1-7): Angiotensin-(17); Angl: Angiotensin 1; Angll: Angiotensin 2; ARDS: Acute respiratory distress syndrome; AT1R: Angll receptor type 1; COX-2: Cyclooxygenase-2; HCoV: Human coronaviruses; KKK: Kallikrein-kininogen-kinin system; N: Viral nucleoprotein protein; NFKB: Nuclear factor kappa-light-chain-enhancer of activated B cells; RAAS: Renin-angiotensin-aldosterone system; RBD: Receptor binding protein; S: Viral spike protein; TMPRSS2: Transmembrane Serine Protease 2

\section{Acknowledgments}

Not applicable.

\section{Authors' contributions}

CJG, RV and DA-P wrote the manuscript and prepared the figures. The authors read and approved the final manuscript.

\section{Funding}

This research was financially supported by the Agencia Nacional De Promoción Científica y Tecnológica (ANPCyT) PICT 2017-3898. FPP acknowledges funding from the Bill and Melinda Gates Foundation. RV acknowledges funding from E2DG

\section{Availability of data and materials}

Because this is a review article, no individual data in any form is included inside the manuscript.

\section{Ethics approval and consent to participate}

Not applicable.

\section{Consent for publication}

Not applicable.

\section{Competing interests}

The authors declare that they have no competing interests.

\section{Author details}

${ }^{1}$ INFANT Foundation, Buenos Aires, Argentina. ${ }^{2}$ CONICET, Buenos Aires, Argentina. ${ }^{3}$ Early Drug Development Group (E2DG), Boulogne-Billancourt, France. ${ }^{4}$ Fondazione Istituto Italiano di Tecnologia, Milan, Italy.

Received: 23 July 2020 Accepted: 15 September 2020 Published online: 22 September 2020

\section{References}

1. Ratification vote on taxonomic proposals to the International Committee on Taxonomy of Viruses (2013) | SpringerLink [Internet]. [cited 2020 Aug 27]. Available from: https://link.springer.com/article/10.1007/s00705-013-1688-5.

2. Hoffmann M, Kleine-Weber H, Schroeder S, Krüger N, Herrler T, Erichsen S, et al. SARS-CoV-2 cell entry depends on ACE2 and TMPRSS2 and is blocked by a clinically proven protease inhibitor. Cell. 2020;0(0) [cited 2020 Apr 4]. Available from: https://www.cell.com/cell/abstract/S0092-8674(20)30229-4.

3. Heurich A, Hofmann-Winkler H, Gierer S, Liepold T, Jahn O, Pöhlmann S. TMPRSS2 and ADAM17 cleave ACE2 differentially and only proteolysis by TMPRSS2 augments entry driven by the severe acute respiratory syndrome coronavirus spike protein. J Virol. 2014;88(2):1293-307.

4. Blais C, Fortin D, Rouleau JL, Molinaro G, Adam A. Protective effect of omapatrilat, a vasopeptidase inhibitor, on the metabolism of bradykinin in normal and failing human hearts. J Pharmacol Exp Ther. 2000;295(2):621-6.

5. Hess DC, Eldahshan W, Rutkowski E. COVID-19-related stroke. Transl Stroke Res. 2020[cited 2020 May 8]; Available from. https://doi.org/10.1007/s12975020-00818-9.

6. Connors JM, Levy JH. COVID-19 and its implications for thrombosis and anticoagulation. Blood. [cited 2020 May 8]; Available from: https:// ashpublications.org/blood/article/doi/10.1182/blood.2020006000/454646/ COVID-19-and-its-implications-for-thrombosis-and.

7. Cao X. COVID-19: immunopathology and its implications for therapy. Nat Rev Immunol. 2020;9:1-2.
8. Wang L, He W, Yu X, et al. Coronavirus disease 2019 in elderly patients: Characteristics and prognostic factors based on 4-week follow-up. J Infect. 2020;80(6):639-45. https://doi.org/10.1016/j.jinf.2020.03.019.

9. Tay MZ, Poh CM, Rénia L, MacAry PA, Ng LFP. The trinity of COVID-19: immunity, inflammation and intervention. Nat Rev Immunol. 2020;20(6):363-74.

10. Merad M, Martin JC. Pathological inflammation in patients with COVID-19: a key role for monocytes and macrophages. Nat Rev Immunol. 2020;20(6): 355-62.

11. Long $Q$, Liu B, Deng, $H$. et al. Antibody responses to SARS-CoV-2 in patients with COVID-19. Nat Med. 2020;26:845-8. https://doi.org/10.1038/s41591-0200897-1.

12. Diao B, Wang C, Tan $Y$, Chen $X$, Liu $Y$, Ning $L$, et al. Reduction and functional exhaustion of T cells in patients with coronavirus disease 2019 (COVID-19). Front Immunol. 2020;11 [cited 2020 Jun 22]. Available from: https://www.frontiersin.org/articles/10.3389/fimmu.2020.00827/full?utm_ source=fweb\&utm_medium =nblog\&utm_campaign=ba-sci-fimmu-covidtcell-exhaustion.

13. Ellinghaus D, Degenhardt F, Bujanda L, et al. Genomewide Association Study of Severe Covid-19 with Respiratory Failure [published online ahead of print, 2020 Jun 17]. N Engl J Med. 2020;NEJMoa2020283. https://doi.org/ 10.1056/NEJMoa2020283.

14. Bornstein SR, Dalan R, Hopkins D, et al. Endocrine and metabolic link to coronavirus infection. Nat Rev Endocrinol. 2020;16:297-8.

15. Teuwen L, Geldhof V, Pasut A, et al. COVID-19: the vasculature unleashed. Nat Rev Immunol. 2020;20:389-91. https://doi.org/10.1038/s41577-020-03430.

16. Li W, Moore MJ, Vasilieva N, Sui J, Wong SK, Berne MA, et al. Angiotensinconverting enzyme 2 is a functional receptor for the SARS coronavirus. Nature. 2003 Nov;426(6965):450-4.

17. Mary D, Frank H, Elizabeth B, Kevin G, Michael G, Nancy S, et al. A novel angiotensin-converting enzyme-related Carboxypeptidase (ACE2) converts angiotensin I to angiotensin 1-9. Circ Res. 2000;87(5):e1-9.

18. Tipnis SR, Hooper NM, Hyde R, Karran E, Christie G, Turner AJ. A human homolog of angiotensin-converting enzyme. Cloning and functional expression as a captopril-insensitive carboxypeptidase. J Biol Chem. 2000; 275(43):33238-43

19. Kuba K, Imai Y, Penninger JM. Multiple functions of angiotensin-converting enzyme 2 and its relevance in cardiovascular diseases. Circ J Off J Jpn Circ Soc. 2013;77(2):301-8.

20. Towler P, Staker B, Prasad SG, Menon S, Tang J, Parsons T, et al. ACE2 X-ray structures reveal a large hinge-bending motion important for inhibitor binding and catalysis. J Biol Chem. 2004;279(17):17996-8007.

21. Turner AJ, Tipnis SR, Guy JL, Rice Gl, Hooper NM. ACEH/ACE2 is a novel mammalian metallocarboxypeptidase and a homologue of angiotensinconverting enzyme insensitive to ACE inhibitors. Can J Physiol Pharmacol. 2002;80(4):346-53.

22. Angiotensin-Converting Enzyme 2 - an overview | ScienceDirect Topics. [cited 2020 Apr 14]. Available from: https://www.sciencedirect.com/topics/ biochemistry-genetics-and-molecular-biology/angiotensin-convertingenzyme-2.

23. Patel $\mathrm{S}$, Rauf $\mathrm{A}$, Khan $\mathrm{H}$, Abu-Izneid T. Renin-angiotensin-aldosterone (RAAS): the ubiquitous system for homeostasis and pathologies. Biomed Pharmacother Biomedecine Pharmacother. 2017;94:317-25.

24. Mirabito Colafella KM, Bovée DM, Danser AHJ. The renin-angiotensinaldosterone system and its therapeutic targets. Exp Eye Res. 2019;186: 107680.

25. Chaszczewska-Markowska M, Sagan M, Bogunia-Kubik K. The reninangiotensin-aldosterone system (RAAS) - physiology and molecular mechanisms of functioning. Postepy Hig Med Dosw (Online). 2016;70(0): 917-27.

26. Xudong $X$, Junzhu $C$, Xingxiang $W$, Furong $Z$, Yanrong L. Age- and gender-related difference of ACE2 expression in rat lung. Life Sci. 2006; 78(19):2166-71.

27. Cheng $H$, Wang $Y$, Wang $G-Q$. Organ-protective effect of angiotensinconverting enzyme 2 and its effect on the prognosis of COVID-19. J Med Virol. 2020[cited 2020 Apr 13]; Available from. https://doi.org/10.1002/jmv. 25785.

28. Sungnak W, Huang N, Bécavin C, Berg M, Network HLB. SARS-CoV-2 entry genes are Most highly expressed in nasal goblet and ciliated cells within human airways. Nat Med. 2020; [cited 2020 May 10]; Available from: http:// arxiv.org/abs/2003.06122. 
29. Allred AJ, Diz DI, Ferrario CM, Chappell MC. Pathways for angiotensin-(1-7) metabolism in pulmonary and renal tissues. Am J Physiol-Ren Physiol. 2000; 279(5):F841-50.

30. Pereira MGAG, Souza LL, Becari C, Duarte DA, Camacho FRB, Oliveira JAC, et al. Angiotensin II-independent angiotensin-(1-7) formation in rat hippocampus: involvement of thimet oligopeptidase. Hypertens Dallas Tex 1979. 2013;62(5):879-85.

31. Santos RA, Brosnihan KB, Jacobsen DW, DiCorleto PE, Ferrario CM. Production of angiotensin-(1-7) by human vascular endothelium. Hypertension. 1992; Feb [cited 2020 Apr 13]; Available from: https://www. ahajournals.org/doi/abs/10.1161/01.hyp.19.2_suppl.ii56.

32. Crackower MA, Sarao R, Oudit GY, Yagil C, Kozieradzki I, Scanga SE, et al. Angiotensin-converting enzyme 2 is an essential regulator of heart function. Nature. 2002 Jun;417(6891):822-8.

33. Bader M. ACE2, angiotensin-(1-7), and mas: the other side of the coin. Pflüg Arch - Eur J Physiol. 2013;465(1):79-85.

34. Silva AS e, Silveira KD, Ferreira AJ, Teixeira MM. ACE2, angiotensin-(1-7) and mas receptor axis in inflammation and fibrosis. Br J Pharmacol. 2013;169(3):477-92.

35. Xiao F, Burns KD. Measurement of angiotensin converting enzyme 2 activity in biological fluid (ACE2). Methods Mol Biol Clifton NJ. 2017;1527:101-15.

36. Zmora P, Hoffmann M, Kollmus H, Moldenhauer A-S, Danov O, Braun A et al. TMPRSS11A activates the influenza a virus hemagglutinin and the MERS coronavirus spike protein and is insensitive against blockade by HAl-1. J Biol Chem. 2018;293(36):13863-73.

37. Shulla A, Heald-Sargent T, Subramanya G, Zhao J, Perlman S, Gallagher T. A transmembrane serine protease is linked to the severe acute respiratory syndrome coronavirus receptor and activates virus entry. J Virol. 2011;85(2): 873-82.

38. Haga S, Yamamoto N, Nakai-Murakami C, Osawa Y, Tokunaga K, Sata T, et al. Modulation of TNF-alpha-converting enzyme by the spike protein of SARSCOV and ACE2 induces TNF-alpha production and facilitates viral entry. Proc Natl Acad Sci U S A. 2008;105(22):7809-14.

39. Glowacka I, Bertram S, Herzog P, Pfefferle S, Steffen I, Muench MO, et al. Differential downregulation of ACE2 by the spike proteins of severe acute respiratory syndrome coronavirus and human coronavirus NL63. J Virol. 2010;84(2):1198-205.

40. Belouzard S, Chu VC, Whittaker GR. Activation of the SARS coronavirus spike protein via sequential proteolytic cleavage at two distinct sites. Proc Natl Acad Sci U S A. 2009;106(14):5871-6.

41. Mathewson AC, Bishop A, Yao Y, Kemp F, Ren J, Chen H, et al. Interaction of severe acute respiratory syndrome-coronavirus and NL63 coronavirus spike proteins with angiotensin converting enzyme-2. J Gen Virol. 2008;89(Pt 11): 2741-5.

42. Wang Q, Zhang Y, Wu L, Niu S, Song C, Zhang Z, et al. Structural and functional basis of SARS-CoV-2 entry by using human ACE2. Cell. 2020; [cited 2020 Apr 12]; Available from: http://www.sciencedirect.com/science/ article/pii/S009286742030338X.

43. Li F. Receptor recognition mechanisms of coronaviruses: a decade of structural studies. Goff SP, editor. J Virol. 2015;89(4):1954-64.

44. Shang J, Wan Y, Luo C, Ye G, Geng Q, Auerbach A, et al. Cell entry mechanisms of SARS-CoV-2. Proc Natl Acad Sci. 2020;117(21):11727-34.

45. Gaddam R, Chambers S, Bhatia M. ACE and ACE2 in inflammation: a tale of two enzymes. Inflamm Allergy-Drug Targets. 2014 Jul 13;13(4): 224-34.

46. Ruiz-Ortega M, Lorenzo O, Suzuki Y, Rupérez M, Egido J. Proinflammatory actions of angiotensins. Curr Opin Nephrol Hypertens. 2001;10(3):321-9.

47. Kuba K, Imai Y, Rao S, Gao H, Guo F, Guan B, et al. A crucial role of angiotensin converting enzyme 2 (ACE2) in SARS coronavirus-induced lung injury. Nat Med. 2005;11(8):875-9.

48. Sodhi CP, Nguyen J, Yamaguchi Y, Werts AD, Lu P, Ladd MR, et al. A dynamic variation of pulmonary ACE2 is required to modulate Neutrophilic inflammation in response to Pseudomonas aeruginosa lung infection in mice. J Immunol. 2019;203(11):3000-12.

49. Ye R, Liu Z. ACE2 exhibits protective effects against LPS-induced acute lung injury in mice by inhibiting the LPS-TLR4 pathway. Exp Mol Pathol. 2020 Apr;113:104350.

50. Yang P, Gu H, Zhao Z, Wang W, Cao B, Lai C, et al. Angiotensin-converting enzyme 2 (ACE2) mediates influenza H7N9 virus-induced acute lung injury. Sci Rep. 2014;4(1):1-6.

51. Gralinski LE, Sheahan TP, Morrison TE, Menachery VD, Jensen K, Leist SR, et al. Complement activation contributes to severe acute respiratory syndrome coronavirus pathogenesis. mBio. 2018;9(5) [cited 2020 Apr 11]. Available from: https://mbio.asm.org/content/9/5/e01753-18.

52. Ye J, Zhang B, Xu J, Chang Q, McNutt MA, Korteweg C, et al. Molecular pathology in the lungs of severe acute respiratory syndrome patients. Am J Pathol. 2007;170(2):538-45.

53. Varga Z, Flammer AJ, Steiger $P$, Haberecker $M$, Andermatt $R$, Zinkernagel AS, et al. Endothelial cell infection and endotheliitis in COVID-19. Lancet. 2020; 395(10234):1417-8.

54. Frantzeskaki F, Armaganidis A, Orfanos SE. Immunothrombosis in acute respiratory distress syndrome: cross talks between inflammation and coagulation. Respir Int Rev Thorac Dis. 2017;93(3):212-25.

55. Luo W, Yu H, Gou J, Li X, Sun Y, Li J, et al. Clinical pathology of critical patient with novel coronavirus pneumonia (COVID-19). 2020; [cited 2020 May 10]; Available from: https://www.preprints.org/manuscript/202002.0407/v1.

56. Chen T, Wu D, Chen H, Yan W, Yang D, Chen G, et al. Clinical characteristics of 113 deceased patients with coronavirus disease 2019: retrospective study. BMJ. 2020;368 [cited 2020 Apr 14]. Available from: https://www.bmj.com/ content/368/bmj.m1091.

57. Wu Z, McGoogan JM. Characteristics of and important lessons from the coronavirus disease 2019 (COVID-19) outbreak in China: summary of a report of 72314 cases from the Chinese Center for Disease Control and Prevention. JAMA. 2020;323(13):1239-42.

58. Wang D, Hu B, Hu C, Zhu F, Liu X, Zhang J, et al. Clinical characteristics of 138 hospitalized patients with 2019 novel coronavirus-infected pneumonia in Wuhan, China. JAMA. 2020;323(11):1061-9.

59. Arentz M, Yim E, Klaff L, Lokhandwala S, Riedo FX, Chong M, et al. Characteristics and outcomes of 21 critically ill patients with COVID-19 in Washington state. JAMA. 2020; [cited 2020 Apr 14]; Available from: https:// jamanetwork.com/journals/jama/fullarticle/2763485.

60. Cao J, Tu W-J, Cheng W, Yu L, Liu Y-K, Hu X, et al. Clinical features and short-term outcomes of 102 patients with Corona virus disease 2019 in Wuhan, China. Clin Infect Dis. [cited 2020 Apr 14]; Available from: https:// academic.oup.com/cid/advance-article/doi/10.1093/cid/ciaa243/5814897.

61. Xu Z, Shi L, Wang Y, Zhang J, Huang L, Zhang C, et al. Pathological findings of COVID-19 associated with acute respiratory distress syndrome. Lancet Respir Med. 2020;8(4):420-2.

62. Danzi GB, Loffi M, Galeazzi G, Gherbesi E. Acute pulmonary embolism and COVID-19 pneumonia: a random association? Eur Heart J. [cited 2020 Apr 14]; Available from: https://academic.oup.com/eurheartj/advance-article/ doi/10.1093/eurheartj/ehaa254/5813284.

63. Klok FA, Kruip MJHA, van der Meer NJM, Arbous MS, Gommers DAMPJ, Kant $\mathrm{KM}$, et al. Incidence of thrombotic complications in critically ill ICU patients with COVID-19. Thromb Res. 2020; [cited 2020 Apr 16]; Available from: http://www.sciencedirect.com/science/article/pii/S0049384820301201.

64. Mao L, Jin H, Wang M, Hu Y, Chen S, He Q, et al. Neurologic manifestations of hospitalized patients with coronavirus disease 2019 in Wuhan, China. JAMA Neurol. 2020; [cited 2020 Apr 16]; Available from: https:// jamanetwork.com/journals/jamaneurology/fullarticle/2764549.

65. Kumar A, Pareek V, Prasoon P, Faiq MA, Kumar P, Kumari C, et al. Possible routes of SARS-COV-2 invasion in brain: in context of neurological symptoms in COVID-19 patients. J Neurosci Res. 2020;00:1-8.

66. Pena-Silva RA, Heistad DD. Stages in discovery: ACE2 and stroke. Hypertension. 2015;66(1):15-6.

67. Bennion DM, Haltigan E, Regenhardt RW, Steckelings UM, Sumners C. Neuroprotective mechanisms of the ACE2-angiotensin-(1-7)-mas axis in stroke. Curr Hypertens Rep. 2015 Feb;17(2):3.

68. Peña SRA, Yi C, Miller Jordan D, Mitchell lan J, Penninger Josef M, Faraci Frank $M$, et al. Impact of ACE2 deficiency and oxidative stress on cerebrovascular function with aging. Stroke. 2012;43(12):3358-63.

69. Long Q-X, Tang X-J, Shi Q-L, Li Q, Deng H-J, Yuan J, et al. Clinical and immunological assessment of asymptomatic SARS-CoV-2 infections. Nat Med. 2020;18:1-5

70. Wang Y, Li X, Liu W, Gan M, Zhang L, Wang J, et al. dif. Emerg Microbes Infect. 2020;9(1):246-55.

71. Hand J, Rose EB, Salinas A, Lu X, Sakthivel SK, Schneider E, et al. Severe respiratory illness outbreak associated with human coronavirus NL63 in a Long-term care facility. Emerging Infect Dis J- CDC. 2018;24(10) [cited 2020 Apr 12]; Available from: https:/wwwnc.cdc.gov/eid/article/24/10/18-0862_article.

72. Galante O, Avni YS, Fuchs L, Ferster OA, Almog Y. Coronavirus NL63induced adult respiratory distress syndrome. Am J Respir Crit Care Med. 2015;193(1):100-1. 
73. Green T, Gonzalez AA, Mitchell KD, Navar LG. The complex interplay between COX-2 and angiotensin II in regulating kidney function. Curr Opin Nephrol Hypertens. 2012;21(1):7-14.

74. Kohlstedt K, Busse R, Fleming I. Signaling via the angiotensin-converting enzyme enhances the expression of cyclooxygenase-2 in endothelial cells. Hypertens Dallas Tex 1979. 2005:45(1):126-32.

75. Fara S, Virginia R, Francisco S, Castells MT, Llinás MT, Javier SF. Hypertension and sex differences in the age-related renal changes when Cyclooxygenase2 activity is reduced during Nephrogenesis. Hypertension. 2009;53(2):331-7.

76. Lebedeva ES, Kuzubova NN, Titova ON, Surkova EA. Effect of cyclooxygenase-2 inhibition on lung inflammation and hypoxia-inducible factor-1 signalling in COPD model. Eur Respir J. 2017;50(suppl 61) [cited 2020 Apr 16]. Available from: https://erj.ersjournals.com/content/50/ suppl_61/PA3926.

77. Surjit M, Lal SK. The SARS-CoV nucleocapsid protein: a protein with multifarious activities. Infect Genet Evol J Mol Epidemiol Evol Genet Infect Dis. 2008;8(4):397-405.

78. Gralinski LE, Menachery VD. Return of the coronavirus: 2019-nCoV. Viruses. 2020;12(2):135

79. Rigat B, Hubert C, Alhenc-Gelas F, Cambien F, Corvol P, Soubrier F. An insertion/deletion polymorphism in the angiotensin l-converting enzyme gene accounting for half the variance of serum enzyme levels. J Clin Invest. 1990;86(4):1343-6.

80. Buikema H, Pinto YM, Rooks G, Grandjean JG, Schunkert H, van Gilst WH The deletion polymorphism of the angiotensin-converting enzyme gene is related to phenotypic differences in human arteries. Eur Heart J. 1996;17(5): 787-94.

81. Marshall RP, Webb S, Bellingan GJ, Montgomery HE, Chaudhari B, McAnulty $\mathrm{RJ}$, et al. Angiotensin converting enzyme insertion/deletion polymorphism is associated with susceptibility and outcome in acute respiratory distress syndrome. Am J Respir Crit Care Med. 2002;166(5):646-50.

82. Itoyama S, Keicho N, Quy T, Phi NC, Long HT, Ha LD, et al. ACE1 polymorphism and progression of SARS. Biochem Biophys Res Commun. 2004:323(3):1124-9.

83. Yende S, Quasney MW, Tolley EA, Wunderink RG. Clinical relevance of angiotensin-converting enzyme gene polymorphisms to predict risk of mechanical ventilation after coronary artery bypass graft surgery*. Read Online Crit Care Med Soc Crit Care Med. 2004;32(4):922-7.

84. Jerng J-S, Yu C-J, Wang H-C, Chen K-Y, Cheng S-L, Yang P-C. Polymorphism of the angiotensin-converting enzyme gene affects the outcome of acute respiratory distress syndrome. Crit Care Med. 2006;34(4):1001-6.

85. Hatami N, Ahi S, Sadeghinikoo A, et al. Worldwide ACE (I/D) polymorphism may affect COVID-19 recovery rate: an ecological meta-regression. Endocrine. 2020;68:479-84. https://doi.org/10.1007/s12020-020-02381-7.

86. Zhou F, Yu T, Du R, Fan G, Liu Y, Liu Z, et al. Clinical course and risk factors for mortality of adult inpatients with COVID-19 in Wuhan, China: a retrospective cohort study. Lancet. 2020;395(10229):1054-62.

87. Nishiga M, Wang DW, Han Y, Lewis DB, Wu JC. COVID-19 and cardiovascular disease: from basic mechanisms to clinical perspectives. Nat Rev Cardiol. 2020;17(9):543-58.

88. Te Riet L, van Esch JHM, Roks AJM, van den Meiracker AH, Danser AHJ. Hypertension: renin-angiotensin-aldosterone system alterations. Circ Res. 2015;116(6):960-75.

89. Gurley SB, Allred A, Le TH, Griffiths R, Mao L, Philip N, et al. Altered blood pressure responses and normal cardiac phenotype in ACE2-null mice. J Clin Invest. 2006;116(8):2218-25.

90. Zamaneh K, Jiuchang Z, Guo D, Ratnadeep B, Wang X, Liu PP, et al. Loss of angiotensin-converting enzyme 2 accelerates maladaptive left ventricular remodeling in response to myocardial infarction. Circ Heart Fail. 2009;2(5):446-55.

91. Bonino B, Leoncini G, De Cosmo S, Greco E, Russo GT, Giandalia A, et al. Antihypertensive treatment in diabetic kidney disease: the need for a patient-centered approach. Medicina (Mex). 2019;55(7) [cited 2020 Apr 16] Available from: https://www.ncbi.nlm.nih.gov/pmc/articles/PMC6681235/.

92. Bindom SM, Lazartigues $\mathrm{E}$. The sweeter side of ACE2: physiological evidence for a role in diabetes. Mol Cell Endocrinol. 2009;302(2):193-202.

93. Oudit GY, Liu GC, Zhong J, Basu R, Chow FL, Zhou J, et al. Human recombinant ACE2 reduces the progression of diabetic nephropathy. Diabetes. 2010;59(2):529-38.

94. Mizuiri S, Hemmi H, Arita M, Ohashi Y, Tanaka Y, Miyagi M, et al. Expression of ACE and ACE2 in individuals with diabetic kidney disease and healthy controls. Am J Kidney Dis Off J Natl Kidney Found. 2008;51(4):613-23.
95. White MC, Fleeman R, Arnold AC. Sex differences in the metabolic effects of the renin-angiotensin system. Biol Sex Differ. 2019;10(1):NA-NA

96. Clotet-Freixas S, Soler MJ, Palau V, Anguiano L, Gimeno J, Konvalinka A, et al. Sex dimorphism in ANGII-mediated crosstalk between ACE2 and ACE in diabetic nephropathy. Lab Investig J Tech Methods Pathol. 2018;98(9): 1237-49.

97. Davies NG, Klepac P, Liu Y, Prem K, Jit M, Eggo RM. Age-dependent effects in the transmission and control of COVID-19 epidemics. Nat Med. 2020; 26(8):1205-11.

98. Kamo T, Akazawa H, Komuro I. Pleiotropic effects of angiotensin II receptor signaling in cardiovascular homeostasis and aging. Int Heart J. 2015;56(3): 249-54.

99. Oudit G, Kassiri Z, Patel M, Chappell M, Butany J, Backx P, et al. Angiotensin II-mediated oxidative stress and inflammation mediate the age-dependent cardiomyopathy in ACE2 null mice. Cardiovasc Res. 2007:75(1):29-39.

100. Booeshaghi AS, Pachter L. Decrease in ACE2 mRNA expression in aged mouse lung [internet]. Mol Biol. 2020; [cited 2020 Aug 31]. Available from: http://biorxiv.org/lookup/doi/10.1101/2020.04.02.021451.

101. Chen J, Jiang Q, Xia X, Liu K, Yu Z, Tao W, et al. Individual variation of the SARS-CoV2 receptor ACE2 gene expression and regulation; 2020. [cited 2020 Apr 5]; Available from: https://www.preprints.org/manuscript/202003. 0191/v1.

102. Casarini DE, Boim MA, Stella RCR, Schor N. Endopeptidases (kininases) are able to hydrolyze kinins in tubular fluid along the rat nephron. Am J Physiol-Ren Physiol. 1999;277(1):F66-74.

103. Vickers C, Hales P, Kaushik V, Dick L, Gavin J, Tang J, et al. Hydrolysis of biological peptides by human angiotensin-converting enzyme-related carboxypeptidase. J Biol Chem. 2002;277(17):14838-43.

104. Campanholle G, Landgraf RG, Gonçalves GM, Paiva VN, Martins JO, Wang $\mathrm{PHM}$, et al. Lung inflammation is induced by renal ischemia and reperfusion injury as part of the systemic inflammatory syndrome. Inflamm Res. 2010; 59(10):861-9.

105. Sodhi CP, Wohlford-Lenane C, Yamaguchi Y, Prindle T, Fulton WB, Wang S, et al. Attenuation of pulmonary ACE2 activity impairs inactivation of desArg9 bradykinin/BKB1R axis and facilitates LPS-induced neutrophil infiltration. Am J Physiol Lung Cell Mol Physiol. 2018;314(1):L17-31.

106. Perez V, Velarde V, Acuna-Castillo C, Gomez C, Nishimura S, Sabaj V, et al. Increased Kinin levels and decreased responsiveness to Kinins during aging. J Gerontol A Biol Sci Med Sci. 2005;60(8):984-90.

107. Siltari A, Korpela R, Vapaatalo H. Bradykinin -induced vasodilatation: role of age, ACE1-inhibitory peptide, mas- and bradykinin receptors. Peptides. 2016; 85:46-55.

108. Mantelli L, Amerini S, Ledda F. Bradykinin-induced vasodilation is changed to a vasoconstrictor response in vessels of aged normotensive and hypertensive rats. Inflamm Res Off J Eur Histamine Res Soc Al. 1995;44(2): 70-3.

109. Schmaier $\mathrm{AH}$. The kallikrein-kinin and the renin-angiotensin systems have a multilayered interaction. Am J Physiol-Regul Integr Comp Physiol. 2003; 285(1):R1-13.

110. Chung HY, Kim HJ, Kim KW, Choi JS, Yu BP. Molecular inflammation hypothesis of aging based on the anti-aging mechanism of calorie restriction. Microsc Res Tech. 2002;59(4):264-72.

111. Stewart KG, Yunlong Z, Davidge Sandra T. Aging increases PGHS-2dependent vasoconstriction in rat mesenteric arteries. Hypertension. 2000; 35(6):1242-7.

112. Lötvall J, Akdis CA, Bacharier LB, Bjermer L, Casale TB, Custovic A, et al. Asthma endotypes: a new approach to classification of disease entities within the asthma syndrome. J Allergy Clin Immunol. 2011;127(2):355-60.

113. Paggi DA, Polack FP. Toward personalized medicine in bronchiolitis. Am J Respir Crit Care Med. 2019;199(12):1456-8.

114. Hasegawa K, Dumas O, Hartert TV, Camargo CA Jr. Advancing our understanding of infant bronchiolitis through phenotyping and endotyping: clinical and molecular approaches. Expert Rev Respir Med. 2016;10(8):891-9.

115. Vaduganathan M, Vardeny $O$, Michel T, McMurray JJV, Pfeffer MA, Solomon SD. Renin-angiotensin-aldosterone system inhibitors in patients with Covid-19. N Engl J Med. 2020;0(0):null.

116. Ferrario CM, Jessup J, Chappell MC, Averill DB, Brosnihan KB, Tallant EA, et al. Effect of angiotensin-converting enzyme inhibition and angiotensin II receptor blockers on cardiac angiotensin-converting enzyme 2. Circulation. 2005;111(20):2605-10. 
117. Hamming I, Van Goor H, Turner AJ, Rushworth CA, Michaud AA, Corvol P, et al. Differential regulation of renal angiotensin-converting enzyme (ACE) and ACE2 during ACE inhibition and dietary sodium restriction in healthy rats. Exp Physiol. 2008:93(5):631-8.

118. Vuille-dit-Bille RN, Camargo SM, Emmenegger L, Sasse T, Kummer E, Jando J, et al. Human intestine luminal ACE2 and amino acid transporter expression increased by ACE-inhibitors. Amino Acids. 2015;47(4):693-705.

119. Rossi GP, Sanga V, Barton M. Potential harmful effects of discontinuing ACEinhibitors and ARBs in COVID-19 patients. elife. 9 [cited 2020 Sep 3]. Available from: https://www.ncbi.nlm.nih.gov/pmc/articles/PMC7198232/.

120. Zhang J, Wang M, Ding W, Wan J. The interaction of RAAS inhibitors with COVID-19: current progress, perspective and future. Life Sci. 2020;257: 118142.

121. Albini A, Di Guardo G, Noonan DM, Lombardo M. The SARS-CoV-2 receptor, ACE-2, is expressed on many different cell types: implications for ACEinhibitor- and angiotensin II receptor blocker-based cardiovascular therapies. Intern Emerg Med. 2020;15(5):759-66.

122. Calcagnile M, Forgez P, lannelli A, Bucci C, Alifano M, Alifano P. ACE2 polymorphisms and individual susceptibility to SARS-CoV-2 infection: insights from an in silico study. bioRxiv. 2020;2020.04.23.057042.

123. KaiserMar. $27 \mathrm{~J}, 2020, \mathrm{Pm} 3: 25$. How sick will the coronavirus make you? The answer may be in your genes [internet]. Science | AAAS. 2020; [cited 2020 Apr 11]. Available from: https://www.sciencemag.org/news/2020/03/howsick-will-coronavirus-make-you-answer-may-be-your-genes.

124. Chakravarty D, Nair SS, Hammouda N, Ratnani P, Gharib Y, Wagaskar V, et al. Sex differences in SARS-CoV-2 infection rates and the potential link to prostate cancer. Commun Biol. 2020;3(1):1-12.

125. Fu Y, Cheng Y, Wu Y. Understanding SARS-CoV-2-mediated inflammatory responses: from mechanisms to potential therapeutic tools. Virol Sin. 2020[cited 2020 Apr 16]; Available from. https://doi.org/10.1007/s12250-02000207-4.

\section{Publisher's Note}

Springer Nature remains neutral with regard to jurisdictional claims in published maps and institutional affiliations.

Ready to submit your research? Choose BMC and benefit from:

- fast, convenient online submission

- thorough peer review by experienced researchers in your field

- rapid publication on acceptance

- support for research data, including large and complex data types

- gold Open Access which fosters wider collaboration and increased citations

- maximum visibility for your research: over $100 \mathrm{M}$ website views per year

At $\mathrm{BMC}$, research is always in progress.

Learn more biomedcentral.com/submissions 